\title{
Development and Introduction of Facebook Teaching Module for First Year Medical Students in Anatomy: A Students' Perspective
}

\author{
Anu Sharma ${ }^{1}$, Daljit Singh ${ }^{2}$, Rajoo Singh ${ }^{3}$, Sheena Singh ${ }^{4}$, Anil Kapoor ${ }^{5}$, Ajay Kumar ${ }^{6}$, \\ Anshu Soni ${ }^{7}$, Apoorva Sharma ${ }^{8}$ \\ ${ }^{1}$ Professor, Department of Anatomy, Dayanand Medical College and Hospital, Ludhiana, Punjab. \\ India. \\ ${ }^{2}$ Vice Chancellor, Sri Guru Ram Das University of Health Sciences, Sri Amritsar, Punjab. \\ ${ }^{3}$ Dean Academics, Dayanand Medical College and Hospital, Ludhiana, Punjab. India. \\ ${ }^{4}$ Professor, Department of Physiology, Christian Medical College, Ludhiana, Punjab, India \\ ${ }^{5}$ Professor of Medicine, People's College of Medical Sciences \& Research Centre, Bhopal. \\ ${ }^{6}$ Professor, Department of Anatomy, Dayanand Medical College and Hospital, Ludhiana, Punjab, \\ India. \\ ${ }^{7}$ Assistant Professor, Department of Anatomy, Dayanand Medical College and Hospital, \\ Ludhiana, Punjab, India. \\ ${ }^{8}$ Intern, Punjab Institute of Medical Sciences, Jalandhar, Punjab, India.
}

Corresponding Author: Apoorva Sharma

E-mail: anuashwani@gmail.com

\begin{abstract}
Background: There is a clear tendency for students to interact on popular social networking sites, such as Facebook and twitter. Any technology that is able to captivate so many students may offer an opportunity for educators to incorporate these social media into teaching and learning. The aim of the study is to look at the introduction of Facebook as a collaborative e-learning tool for medical students in the subject of anatomy and to explore their perspectives on its usage.

Methodology: The teaching innovation project involved first year MBBS students. 47 students out of a batch of seventy consented to be members of Facebook closed group related with anatomy learning in the region of abdomen and pelvis. Videos, texts, quizzes and diagrams of the related region were periodically uploaded. The validity and effectiveness of Facebook as an educational tool was analyzed on the basis of qualitative questionnaires, focus group discussions (FGDs), responses on facebook.to generate data for understanding perspectives in elaborated form.

Results: Almost $60 \%$ of students agreed that social networking time was put to good educational use, $19 \%$ of the students strongly disagreed for the same while $21 \%$ remained neutral. FGDs and interview notes established Facebook as a good educational tool. $77 \%$ of students advocated Facebook usage for successive batches in the subject of anatomy. Faculty also found the concept of using Facebook for education as an interesting tool, and suggested its' use in all anatomy regions through Facebook-anatomy page.

Conclusion: Facebook must be explored as an educational tool for medical students and as an interactive learning platform.
\end{abstract}

Keywords: Facebook, Teaching innovation project, feedback, educational tool. 


\section{INTRODUCTION}

Facebook is an environment in which students are very comfortable. The study was conducted to explore students' perspectives for using Facebook as an educational tool. Facebook, has evolved into the most visited social networking site in the world with over 750 million active users [1]. Educationists on Facebook may play significant role by allowing easy access of educational content including their contact information to students as users [2]. Students will be more likely to view their teachers as someone that is ready to help in academics in student friendly environment [3]. This in long run will help students for learning throughout their career by interacting with their subject facilitators.

\section{METHODOLOGY}

The teaching innovation project involved first year MBBS students for anatomy teaching in the region of abdomen \& pelvis. Students were briefed about the subject and topic related teaching intervention on Facebook. 47 students out of a batch of seventy volunteered for participation in anatomy teachings on Facebook. These students were already having devices (laptop/computers/smart phones/tablets) and internet connections to communicate on Facebook. Participant informed consent forms were filled \& taken from those students who volunteered themselves for the Facebook anatomy education. A group name was provided, privacy of the group maintained and members were added in the group. Educational material was periodically uploaded in the form of videos, texts, quizzes and diagrams of the related region. Almost ten modules consisted of videos, pictures, lectures related with abdomen and pelvis region were uploaded over a period of eight weeks coinciding with abdomen \& pelvis teachings in anatomy classroom. Each student in a group was encouraged to study and interact on Facebook. Some of the students did real time chat on relevant topics on Facebook. Written feedback form on perspectives in the form of questionnaire was prepared [4]. Filled forms were collected from students and analysed, after they got through the first professional examination. The effectiveness of Facebook as an educational tool was analysed on the basis of qualitative questionnaires, focus group discussions, interviews and responses on Facebook. Through all these methods, we could collect data for understanding the subject matter in its proper perspective. It was hypothesized that deep theoretical information of this data would help us in understanding the subject and for arriving at evidence-based decision making to use Facebook as an educational tool. Kruger's guide book was used to analyse FGDs and interviews [5]. Informal faculty feedback on issues like logistics, student's motivation and impact was also taken and compiled. Faculty was also involved in making anatomy modules to post on Facebook.

Implementation: Permission to carry out the project and ethical waiver was granted by IEC. Student information sheets and informed consent forms and related anatomy modules in the forms of videos, texts, diagrams and questioning were prepared. Relevant anatomy topic modules were uploaded weekly/bi weekly on the Facebook group coinciding with class room teachings. Their responses on Facebook were seen. Wherever required, queries were responded to. Feedback questionnaires for students were designed in consultation with colleagues and some of the FAIMER faculty facilitators.

Counselling of students: The counselling sessions were held in the students' common room, lecture theatre, in library lounge or office chamber or at times in the hostel to motivate and help them develop interest in collaborative learning. Only the student and the investigator were present in the counselling session and each session took about 15-20 minutes. During counselling, the learning practices of students were discussed. Adequate care was taken that the student did not feel being stereotyped as a learner. The aim was to give an overview of his learning preferences. The students were encouraged to share the problems they faced in studying and in attending classes. Appropriate suggestions were made. The students were encouraged for collaborative learning.

Discussion with faculty and sensitization: Before starting the region, faculty in the department was sensitized for this Facebook group. Modules were validated by the faculty prior to their 
release. The faculty validated feedback forms for the students . Informal faculty feedback related to logistics, student motivation and impact was taken and salient features were noted.

Collection of Data: The data was collected and analysed. The students and faculty feedback were taken.

\section{RESULTS}

Response on the Facebook: Responses of the students to each educational post in the form of 'Seen by' 'likes' and 'comments' were recorded in the form of bar chart (Fig 1).

Figure 1 - Student's responses on Facebook

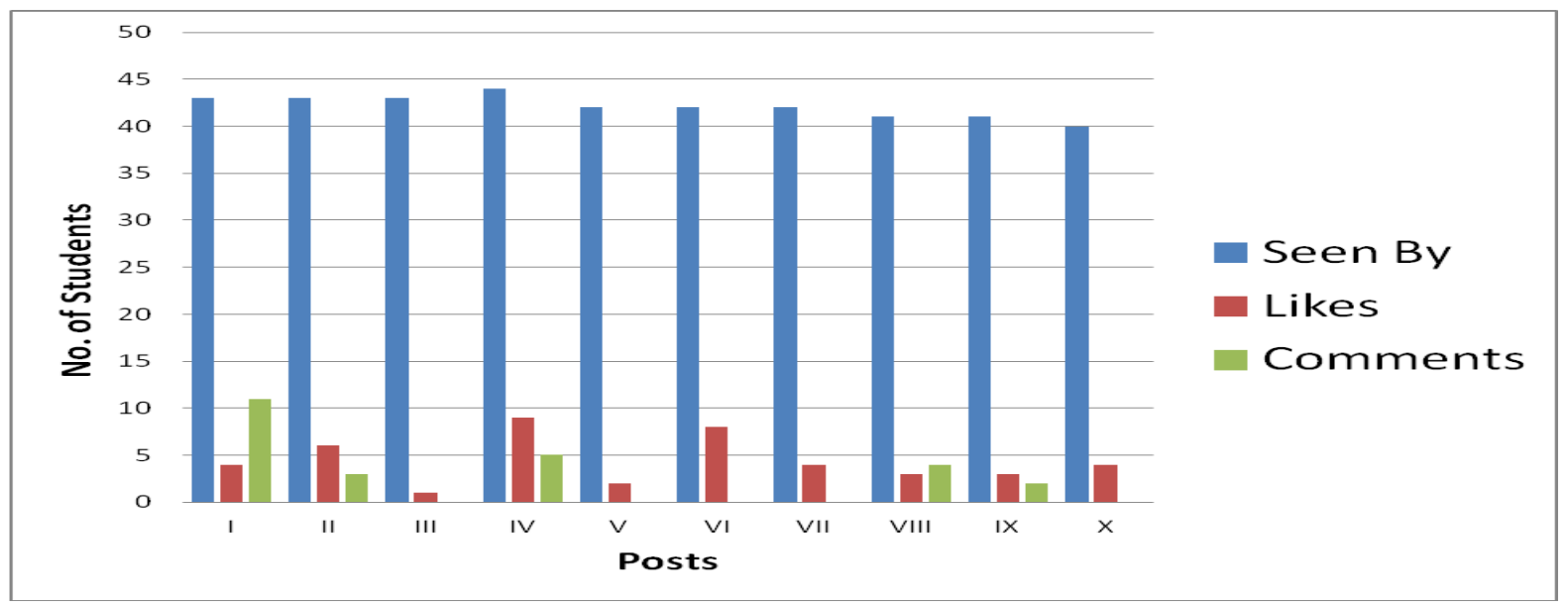

Feedback from students: The feedback from student participants in the study was collected in a paper format after they had cleared the first professional examination (as directed by IEC) The responses to qualitative questionnaire were tabulated (Table 1-4).

Table 1 - Feedback form for learning perception on a 5 point likert scale $(n=47)$

\begin{tabular}{|c|c|c|c|c|c|c|}
\hline & Questionnaire item & SA & A & N & D & SD \\
\hline 1 & The teaching helps to develop my confidence & 5 & 14 & 20 & 5 & 3 \\
\hline 2 & I am clear about learning objectives of the course & 4 & 10 & 20 & 11 & 2 \\
\hline 3 & The teaching encourages me to be an active learner & 11 & 25 & 5 & 6 & - \\
\hline 4 & Beneficial to reflect on concepts for longer & 35 & 6 & 4 & 2 & - \\
\hline
\end{tabular}

$\mathrm{SA}=$ Strongly Agree, $\mathrm{A}=$ Agree, $\mathrm{N}=$ Neutral, $\mathrm{D}=$ Disagree, $\mathrm{SD}=$ Strongly Disagree

Table 2 - Feedback form for Academic Self-perception on a 5 point likert scale $(n=47)$

\begin{tabular}{|c|c|c|c|c|c|c|}
\hline & Questionnaire item & SA & A & N & D & SD \\
\hline 1 & My problem solving skills are being well developed here & 10 & 20 & 9 & 5 & 3 \\
\hline 2 & Learning strategy on Facebook seems relevant in medical career & 4 & 21 & 13 & 6 & 3 \\
\hline 3 & Beneficial for my course & 9 & 21 & 10 & 5 & 2 \\
\hline
\end{tabular}

$\mathrm{SA}=$ Strongly Agree, $\mathrm{A}=$ Agree, $\mathrm{N}=$ Neutral, $\mathrm{D}=$ Disagree, $\mathrm{SD}=$ Strongly Disagree

Students FGD Notes: Students were called in groups of 7-10 for FGD. One of the students was chosen to be an assistant moderator, who was not participating in the project study. He took notes of the discussions. Five such FGDs were scheduled to record the responses of use of Facebook as an education tool. The FGDs record was compiled. The notes revealed certain important aspects. 
Table 3 - Student feedback form for information processing on a 5 point likert scale $(n=47)$

\begin{tabular}{|c|c|c|c|c|c|c|}
\hline & Questionnaire item & SA & A & N & D & SD \\
\hline 1 & The content is increasing my interest in learning more about this Area & 7 & 17 & 15 & 6 & 2 \\
\hline 2 & The ready reference to the posts available on FB was beneficial to me & 11 & 20 & 10 & 5 & 1 \\
\hline 3 & Our queries were readily responded & 10 & 23 & 12 & 2 & - \\
\hline 4 & Student volunteered their own opinions & 11 & 25 & 5 & 6 & - \\
\hline 5 & Teaching facilitator was friendly & 5 & 14 & 20 & 5 & 3 \\
\hline
\end{tabular}

$\mathrm{SA}=$ Strongly Agree, $\mathrm{A}=$ Agree, $\mathrm{N}=$ Neutral, $\mathrm{D}=$ Disagree, $\mathrm{SD}=$ Strongly Disagree

Table 4 - Student feedback form for Perception of edusocial atmosphere $(n=47)$

\begin{tabular}{|c|c|c|c|c|c|c|}
\hline & Questionnaire item & SA & A & N & D & SD \\
\hline 1 & The atmosphere motivates me as a learner & 11 & 25 & 5 & 6 & - \\
\hline 2 & 'At ease' environment for learning & 20 & 11 & 9 & 7 & - \\
\hline 3 & $\begin{array}{c}\text { There is a good support system for students who } \\
\text { get stressed }\end{array}$ & 18 & 20 & 7 & 2 & - \\
\hline 4 & Social networking time is put to good use & 7 & 21 & 10 & 6 & 3 \\
\hline 5 & $\begin{array}{c}\text { I advocate use of this program in successive } \\
\text { batches for course of anatomy }\end{array}$ & 11 & 25 & 5 & 6 & - \\
\hline
\end{tabular}

$\mathrm{SA}=$ Strongly Agree, $\mathrm{A}=$ Agree, $\mathrm{N}=$ Neutral, $\mathrm{D}=$ Disagree, $\mathrm{SD}=$ Strongly Disagree

Salient features of student's perspectives are as -

Strengths:

1. Simplicity of use makes it user friendly

2. Powerful support for mobile learning

3. Easy to use on operating systems like ios, Android etc.

4. Flexibility and convenience were indispensable

5. Availability of teacher inside and outside the class

6. Improves student teacher interaction

Weaknesses:

1. Closed privacy of a group as a hindrance- in sharing the content with non- members of the group.

2. Facebook group discussion boards as very basic. They felt that the site lacks a system for organizing messages to facilitate searches on them.

3. Inability to create events by participants.

4. Distractions on Facebook act as a hindrance to study. Felt shy in creating and sharing experiences.

5. 'Whatsapp' could have been more convenient, accessible and user-friendly educational tool.

Faculty Feedback: Salient points from informal discussion with the faculty were found to be varied. The concept of using Facebook to promote collaborative learning amongst students was thought of as interesting and helpful by few. On the other hand, few were totally avert to the idea of using Facebook for education. Introduction of Facebook seemed to be a novel idea by some, but better could be if incorporated in all the regions through Facebook page.

\section{DISCUSSION}

This study found that first year medical students who participated in the study feel positive about collaborative learning on Facebook. 50\% of the student felt Facebook learning beneficial for their course, which is conforming to earlier study [6]. Students felt happy on its usefulness in synchronous communication. They were able to detect which members or friends were online and 
could initiate real - time chat with other group members [7] and to an educational facilitator.The present work also revealed impact of edusocial space on students motivation. Most of the students (78\%) felt motivated to learn on this edusocial space. However, further study on overall academic report of students to this type of collaborative learning throughout the course, would bring better correlation. That study would be continuum of this novel exercise on collaborative learning on Facebook. Additional research is also needed to explore the most beneficial design for an edusocial space [8].

\section{CONCLUSIONS}

Most of the first-year medical students gave positive response for using educational space for their learning process. Shy students in classroom also felt 'at ease' to interact in this user-friendly environment. The atmosphere showed a shift of students mind to adult learning theory in which learning and interest both got enhanced by learner's interactions with others. Integration of this innovative Facebook learning into medical education is an initiation to implement motivational strategies in learning process that would help in long run. The students will utilize network site and line to meet their educational needs. It will help us in building a platform, where educators will no longer serve mainly as the distributor of content, but will become more involved as facilitators of learning and assessors of competency.

\section{REFERENCES}

1. Palo Alto, CA Facebook. 2011. Press Room, Statistics.: Avaolaible at :http://www.Facebook.com/press/info.php?statistics Accessed on July 19, 2011

2. Mack D, Behler A, Roberts B, Rimland E. Reaching students with Facebook: Data and best Practices. Electronic J Acad Spec Libr 2007;8(2).

3. Bin Abdulrahman KA. Students' views on student-teacher relationship: a questionnaire-based study. J Fam Commun Med 2007;14(2):81-7.

4. Enerson DM, Munooz TD, Johnson RN, Plank KM. Feedback Questionnaire: A guide for new teachers. Office of instruction development, UCLA (Los Angeles):1995.

5. Krueger RA, Casey MA. Focus Groups: A Practical Guide for Applied Research. 3rd ed. Thousand Oaks, CA: Sage Publications 2000.

6. Margarita V, DiVall D, Jennifer L, Kirwin D. Using Faebook to facilitate course related discussion between students and faculty members. Am J Pharm Educ 2012;76(2):1-5.

7. Cerdà FL, Planas NC. Facebook's Potential for Collaborative e-Learning. RUSC 2011;8(2):197210.

8. Ruiz JG, Mintzer MJ, Leipzig RM. The impact of e-learning in medical education. Acad Med 2006;81(3):207-12.

Acknowledgements: Nil

Funding: Nil

Conflict of Interest: Nil 